Sexual behavior, cannibalism, and mating plugs as sticky traps in the orb weaver spider Leucauge argyra (Tetragnathidae)

Anita Aisenberg \& Gilbert Barrantes

Naturwissenschaften

The Science of Nature

ISSN 0028-1042

Volume 98

Number 7

Naturwissenschaften (2011)

98:605-613

DOI 10.1007/s00114-011-0807y

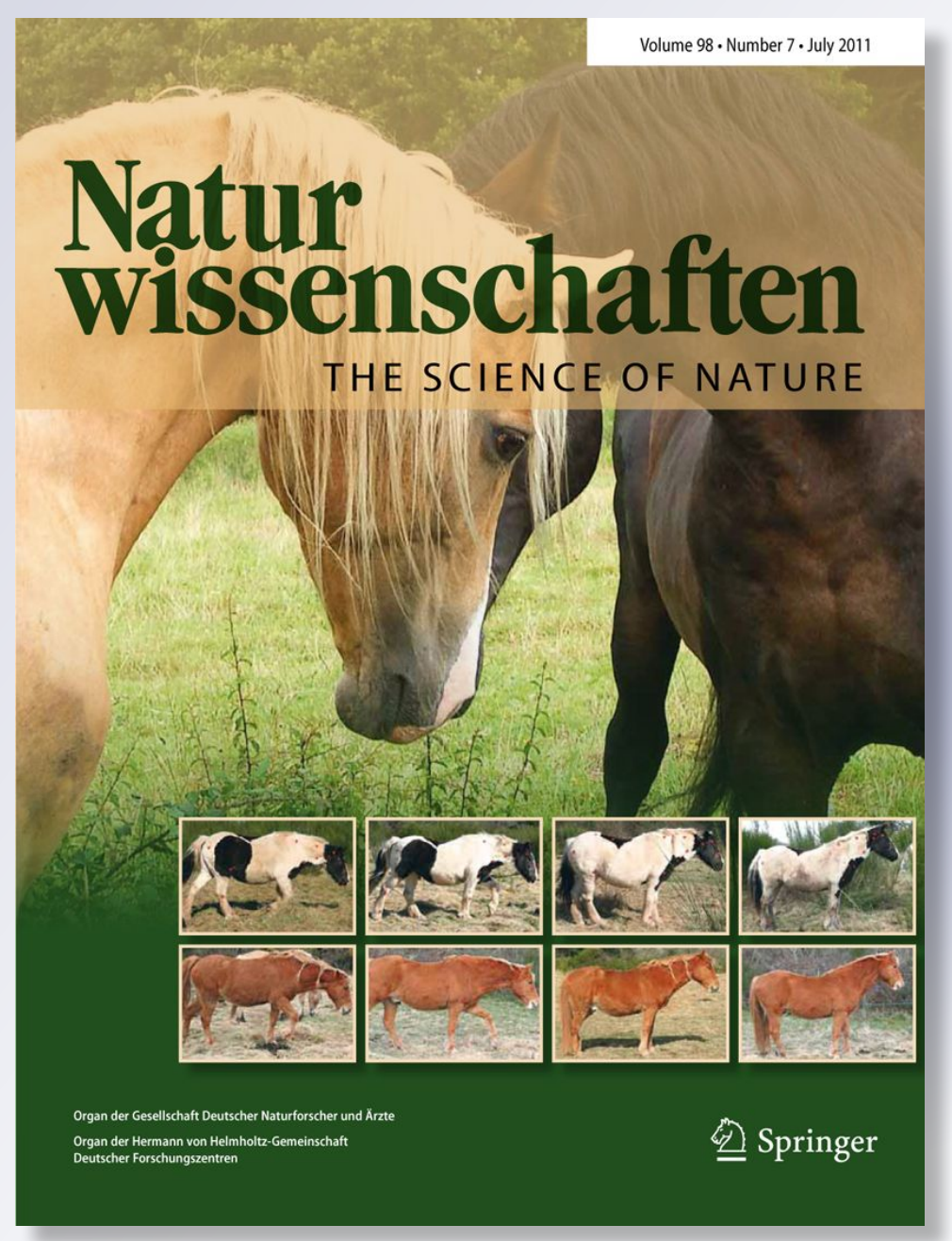

望 Springer 
Your article is protected by copyright and all rights are held exclusively by SpringerVerlag. This e-offprint is for personal use only and shall not be self-archived in electronic repositories. If you wish to self-archive your work, please use the accepted author's version for posting to your own website or your institution's repository. You may further deposit the accepted author's version on a funder's repository at a funder's request, provided it is not made publicly available until 12 months after publication. 


\title{
Sexual behavior, cannibalism, and mating plugs as sticky traps in the orb weaver spider Leucauge argyra (Tetragnathidae)
}

\author{
Anita Aisenberg • Gilbert Barrantes
}

Received: 5 April 2011 /Revised: 6 May 2011 /Accepted: 7 May 2011/Published online: 24 May 2011

(C) Springer-Verlag 2011

\begin{abstract}
Unpublished field observations in Leucauge argyra, a tropical orb weaver spider, suggest the occurrence of conspicuous mating plugs that could reduce or prevent remating attempts. Otherwise, the sexual behavior of this species remains unknown. The aims of this study were to describe the courtship behavior and copulation in L. argyra and investigate mating plug formation in this species. Fourteen virgin females and 12 plugged females were exposed to up to three males and checked for mating plug formation. Of the 12 virgins that copulated, nine produced plugs (five immediately after copulation), and the five plugged females that copulated produced another mating plug immediately after copulation. We did not detect the transfer of any male substance during copulation but observed a whitish liquid emerging from female genital ducts. Plug formation was positively associated with male twanging during courtship. One virgin and four plugged females cannibalized males. In seven trials with virgins and in three trials with plugged females, the male's palp adhered to a substance that emerged from female genital ducts and spread on her genital plate. The male had to struggle energetically to free his glued palp; two of these males were cannibalized while trying to release their palps. Females
\end{abstract}

Communicated by: Sven Thatje

A. Aisenberg $(\bowtie)$

Laboratorio de Etología, Ecología y Evolución,

Instituto de Investigaciones Biológicas Clemente Estable,

Av. Italia 3318,

CP 11600 Montevideo, Uruguay

e-mail: aisenber@iibce.edu.uy

\section{G. Barrantes}

Escuela de Biología, Universidad de Costa Rica,

Ciudad Universitaria,

San José, Costa Rica seem to determine copulation duration by altering the timing of mating plug formation and through sexual cannibalism. This is the first case reported of a mating plug as a sticky trap for males.

Keywords Genital plug · Plug removal · Sexual cannibalism $\cdot$ Sexual selection

\section{Introduction}

Mating plugs are widespread in various animal taxa, from insects and arachnids to reptiles, birds, and mammals (Drummond 1984; Andrade 1996; Gomiendo et al. 1998; Knoflach 1998; Wigby and Chapman 2004; Simmons 2001; Mattoni and Peretti 2004; Aisenberg and Eberhard 2009; Leonard and Córdoba-Aguilar 2010; Uhl et al. 2010). These plugs are composed by sperm, glandular products, parts of spermatophores or male genitalia, and in some cases the male's entire body that remains attached to female genitalia (Uhl et al. 2010). Mating plugs are thought to function primarily to prevent or minimize female future mating attempts and consequently, favor the paternity of the copulating male. However, plugs could also have other functions presumably beneficial to females as prevent sperm desiccation or minimize sperm loss (Boorman and Parker 1976; Huber 1995, 2005; Simmons 2001; Uhl et al. 2010).

Though most mating plugs consist of parts of male genitalia or substances transferred by males, in some cases they are formed by a mixture of female and male transferred substances or exclusively by female substances (Méndez 2004; Uhl et al. 2010). In the orb-weaving spider Leucauge mariana (Keyserling 1881) (Tetragnathidae), substances transferred by both sexes are necessary to compose an efficient mating plug (Eberhard and Huber 
1998; Méndez 2004; Aisenberg and Eberhard 2009). Larger numbers of short male genital insertions and of rhythmic pushes of the male's front legs against female's legs during copulation are associated with a higher probability of female supplying her substance and efficient plug formation in this species (Aisenberg and Eberhard 2009). This was the first description of female participation in mating plug formation as a possible mechanism of cryptic female choice based on female selection on the basis of male copulatory courtship.

The genus Leucauge White 1841 comprises more than 100 spider species, but sexual behavior has been studied in only few species (Eberhard and Huber 1998). Male copulatory courtship seems to be widespread in this genus (Eberhard 1994; Castro 1995; Eberhard and Huber 1998) and mating plugs have been observed at least in three species: L. mariana, Leucauge venusta (Walckenaer 1841) and Leucauge argyra (Walckenaer 1841) (Castro 1995; Eberhard and Huber 1998). Cheliceral clasping between sexes prior to copulation also occurs in these three Leucauge species, though it is absent or varies (males seize female chelicerae) in other species of Tetragnathidae (Eberhard 1994; Castro 1995; Eberhard and Huber 1998; Aisenberg and Eberhard 2009; Aisenberg 2009). Spiders of this genus are thus interesting for studies of sperm competition, female choice, and the evolution of mating strategies.

L. argyra is an orb-weaving spider that constructs approximately horizontal orb webs in lowland wet areas in Costa Rica (Eberhard 2001). In some sites, this species is extremely abundant year round and during the rainy season males are frequently observed guarding penultimate female close to molt (W.G. Eberhard, G. Barrantes and A. Aisenberg, unpublished data). Unpublished field observations show that females of this species have conspicuous mating plugs largely covering their epigyna; their sexual behavior, however, is unknown. The objectives of this study were to describe courtship and copulation in $L$. argyra and investigate mating plug formation in this species. Additionally, we tested whether plug production is related to female and/or male sexual behavior and tried to elucidate the effectiveness of genital plugs in preventing female rematings.

\section{Materials and methods}

We collected 14 penultimate females, 12 adult females with genital plugs that covered entirely their epigynum, and 35 adult males from September to December 2009 in plantations of African oil palm near Parrita, Puntarenas Province, Costa Rica $\left(09^{\circ} 30^{\prime} \mathrm{N}, 84^{\circ} 10^{\prime} \mathrm{W}\right.$; elevation $\left.10 \mathrm{~m}\right)$. Penultimate females were recognized in the field by being accompanied by an adult male in their webs, as occurs with L. mariana (Eberhard et al. 1993). We obtained virgin adult females by allowing penultimate females to molt in captivity. Each penultimate female was maintained in a cylindrical glass jar $(5-10 \mathrm{~cm}$ diameter and $8 \mathrm{~cm}$ height) covered with a thin mesh lid and was monitored everyday to record molting occurrence. Each jar was provided with a piece of wet cotton and two small branches with leaves.

After molting to maturity, each virgin female $(n=14)$ and each female collected at the field with a complete genital plug $(n=12)$ was placed on a glass terrarium of $30 \mathrm{~cm}$ length, $16 \mathrm{~cm}$ width, and $20 \mathrm{~cm}$ height. We attached a cardboard horizontal frame near the top as substrate for web construction and placed a small plant inside the terrarium to provide humidity and an additional substrate for construction of the web. Spiders were offered a prey three times a week: a Tenebrio molitor larvae (Tenebrionidae) or an adult fly (Sarcophagidae or Calliphorideae). The plants were sprayed everyday with water.

Between 1 and 5 days after the female molted to maturity or 5 days after an adult female with a genital plug had been captured, each female was exposed to one male that was placed on the border of the orb web. If the female did not mate after $30 \mathrm{~min}$ of male courtship, she was exposed to a second male within $1 \mathrm{~h}$ and then to a third male if the second was not accepted. Females that rejected three consecutive males were discarded. If spiders courted but did not copulate, we ended the trial when one spider abandoned the terrarium, when both spiders remained motionless for $15 \mathrm{~min}$, or when the female attacked and injured the male or cannibalized him. For determining periods of experimentation, we followed previous studies on L. mariana (Aisenberg 2009; Aisenberg and Eberhard 2009) and preliminary observations on the study species.

Individuals were used once and were randomly assigned to each trial. The temperature during the trials averaged $24.44 \pm 1.46^{\circ} \mathrm{C}$, range: $21-26$. The arena was illuminated with a fiber optic lamp and all trials were recorded with a SONY DCR TRV50 digital video camera (SONY, San Diego, CA, USA) equipped with +4 close-up lenses. Immediately after copulation, each female was observed and photographed under a Wild model M3Z dissecting microscope (Wild Company, New York, USA), to check for mating plug occurrence, and was checked again $24 \mathrm{~h}$ later. All plugged females were inspected before the expositions and after copulation to check if mating plugs were intact or presented slits. Partial plugs were those mating plugs that covered only part of female epigynum, in contrast to complete plugs that covered both inseminatory duct orifices of the epigynum. We checked male palps after copulation under the dissecting microscope looking for evidence of secretion. We measured carapace width as an estimator of body size in spiders (Eberhard et al. 1998; Moya-Laraño and Cabeza 2003) and tibia length as an estimator of leg length 
(Foellmer and Fairbairn 2004) under a dissecting microscope. We calculated the sexual size dimorphism index (male caparace width/female carapace width) to examine its effect on mating acceptance and plug formation.

We analyzed courtship and copulatory behavior of females and males using Jwatcher program (Blumstein et al. 2000). Detailed analyses of courtship and copulatory behavior provided information for a full description of the sexual behavior of this species and for examining the relationship between courtship and copulatory behaviors, mating acceptance, and plug occurrence. The definitions of courtship and copulatory behaviors follow Robinson and Robinson (1980) and Eberhard and Huber (1998). We recorded the number and duration of courtship and copulatory behavioral units performed by females and males, and compared the results between virgin and plugged females. We also counted the number of hematodochal inflations per insertion, characteristic associated with sperm transfer in spiders (Foelix 1996). To investigate the relation between courtship and copulatory behaviors and plug occurrence, we used only data from virgin females because all plugged females produced plugs after mating. For the comparisons between females, we included courtship and copulatory behaviors that had a total sample size of at least $n=5$ for each category. We considered that a plug was formed when the epigynum was partially or totally covered by a hard whitish substance.We compared the frequencies of copulation, plug formation, and cannibalism frequencies with chi-square test for independent samples and Fisher's exact probability test. The statistical analyses were performed with Past Palaeontological Statistics, version 1.18 (Hammer et al. 2003), NCSS 2001 (Copyright 2000 Jerry Hintze), and WINPEPI (Abramson 2004).

\section{Results}

Description of sexual behavior and plug puncturing behavior

We identified six courtship and five copulatory behaviors (Tables 1 and 2). Three of these behaviors (jerk the web, bursts of twanging, and tap the web) were performed by

Table 1 Descriptions of courtship behavior of L. argyra, with their corresponding frequency and durations (median \pm quartile)

\begin{tabular}{|c|c|c|c|}
\hline Courtship behavior & Description & Frequency & Duration (s) \\
\hline Jerk the web & $\begin{array}{l}\text { Facing the other sex, the female or male } \\
\text { flexes legs I and II strongly and quickly } \\
\text { without releasing the silk line }\end{array}$ & $\begin{array}{l}\text { Female jerk, virgins, } \\
5(n=1) \text { plugged }^{\mathrm{a}} \\
\text { Male jerk, virgins, } 3.0 \pm 6.0 \\
(n=7) ; \text { plugged, } 4.5 \pm 1 \\
(n=2) ; U=4.5, p=0.90\end{array}$ & $\begin{array}{l}\text { Female jerk, virgins, } \\
13(n=1) \text { plugged }^{\mathrm{a}} \\
\text { Male jerk, virgins, } 16.2 \pm 21.3 \\
\left(\begin{array}{l}n=7) ; \text { plugged, } 63.3 \pm 84.0 \\
(n=2) U=2, p=0.22\end{array}\right.\end{array}$ \\
\hline Bursts of palpal rubbing & $\begin{array}{l}\text { Alternate and circular movements of the } \\
\text { palps, during which right and left male } \\
\text { cymbium hooks contact or brush } \\
\text { against each other }\end{array}$ & $\begin{array}{l}\text { Virgins, } 24.0 \pm 21.0(n=12) \\
\text { plugged, } 47 \pm 53(n=5) \\
U=23, p=0.64\end{array}$ & $\begin{array}{l}\text { Virgins, } 111.5 \pm 91.1(n=12) \\
\text { plugged, } 288.1 \pm 279.6(n=5) \\
U=25, p=0.83\end{array}$ \\
\hline $\begin{array}{l}\text { Bursts of twanging } \\
\text { (silk thread tension } \\
\text { and release) }\end{array}$ & $\begin{array}{l}\text { The female or male folds legs III ventrally } \\
\text { and rapidly tensioning the silk } \\
\text { line that connects the two individuals } \\
\text { and then the tension is suddenly } \\
\text { released }\end{array}$ & $\begin{array}{l}\text { Female twanging, virgins: } \\
\quad 2.0 \pm 48(n=12) ; \text { plugged, } \\
5.0 \pm 3(n=5) ; U=15, p=0.17 \\
\text { Male twanging, virgins, } 49.0 \pm 40 \\
\quad(n=12) ; \text { plugged, } 56.0 \pm 91 \quad(n=5) ; \\
\quad U=25, p=0.83\end{array}$ & $\begin{array}{l}\text { Female twanging, virgins, } 6.3 \pm 53.1 \\
\quad(n=12) ; \text { plugged, } 32.1 \pm 19.9(n=5) ; \\
U=17, p=0.37 \\
\text { Male twanging: virgins, } 220.8 \pm 105.5 \\
\quad(n=12) ; \text { plugged } 377.7 \pm 550.8 \\
\quad(n=5) ; U=21, p=0.51\end{array}$ \\
\hline Tap the female & $\begin{array}{l}\text { The male taps the female on the dorsum } \\
\text { of the carapace or on her legs I or II } \\
\text { with his anterior leg tarsi or metatarsi }\end{array}$ & $\begin{array}{l}\text { Virgins, } 4.0 \pm 7.0(n=5) ; \text { plugged, } \\
2.0 \pm 3.0(n=5) ; U=7.5, p=0.58\end{array}$ & $\begin{array}{l}\text { Virgins, } 84.9 \pm 128.9(n=5) \text {; plugged, } \\
\quad 3.3 \pm 6.6(n=5) ; U=1, p=0.12\end{array}$ \\
\hline Tap the web & $\begin{array}{l}\text { The female or the male performs quick } \\
\text { taps with the forelegs on the silk line } \\
\text { that connects both individuals }\end{array}$ & $\begin{array}{l}\text { Female tapping, virgins, } 8.0 \pm 6.0 \\
\quad(n=9) ; \text { plugged, } 16.0 \pm 18.0(n=5) ; \\
\quad U=14, p=0.28 \\
\text { Male tapping, virgins, } 15.0 \pm 11.0 \\
\quad(n=12) ; \text { plugged, } 5.0 \pm 23.0(n=5) ; \\
\quad U=19.5, p=0.40\end{array}$ & $\begin{array}{l}\text { Female tapping, virgins, } 21.4 \pm 82 \\
\quad(n=9) ; \text { plugged, } 60.7 \pm 195.7(n=5) ; \\
U=18, p=0.16 \\
\text { Male tapping, virgins, } 54.5 \pm 105.9 \\
\quad(n=5) ; \text { plugged, } 26.1 \pm 190.1 \\
\quad(n=5) ; U=24, p=0.74\end{array}$ \\
\hline Foreleg rubbing & $\begin{array}{l}\text { The male rubs legs I and II against each } \\
\text { other, after contacting the female web }\end{array}$ & $\begin{array}{l}\text { Virgins, } 2.0 \pm 2.0(n=5) ; \text { plugged, } \\
\begin{array}{l}4.5 \pm 2.5(n=4) \\
U=6.5, p=0.45\end{array}\end{array}$ & $\begin{array}{l}\text { Virgins, } 9.4 \pm 7.0(n=5) ; \text { plugged, } \\
24.9 \pm 22.9(n=4) ; U=9 \\
p=0.03\end{array}$ \\
\hline
\end{tabular}

We distinguish between trials with virgin and plugged females and show the results of the statistical comparisons between both groups (MannWhitney $U$ test). Sample sizes are shown in parentheses

${ }^{\text {a }}$ Insufficient sample size for performing statistical comparisons 
Table 2 Descriptions of copulatory behaviors of L. argyra, with their corresponding frequency and duration (median \pm quartile)

\begin{tabular}{|c|c|c|c|}
\hline Copulatory behavior & Description & Frequency & Duration (s) \\
\hline Long insertions & $\begin{array}{l}\text { Multiple hematodochal inflations } \\
\text { after a single insertion. }\end{array}$ & $\begin{array}{l}\text { Virgins, } 3.0 \pm 1.0(n=12) \\
\text { plugged, } 2.0 \pm 3.0(n=5) \\
U=26, p=0.86\end{array}$ & $\begin{array}{l}\text { Virgins, } 343.6 \pm 173.2(n=12) \\
\text { Plugged, } 235.2 \pm 286.7(n=5) \\
U=16, p=0.22\end{array}$ \\
\hline Inflations & Hematodochal expansions & $\begin{array}{l}\text { Virgins, } 208.0 \pm 139.0(n=12) \\
\text { plugged, } 119.0 \pm 83.0(n=5) \\
U=13.5, p=0.12\end{array}$ & $\begin{array}{l}\text { The duration coincides with } \\
\text { long insertions duration }\end{array}$ \\
\hline Flubs & $\begin{array}{l}\text { Failed insertion attempts. The hematodochae } \\
\text { inflates but the embolus scrapes the epigynum } \\
\text { without engaging it as in a successful insertion, } \\
\text { or briefly engaging it at an inappropriate site }\end{array}$ & $\begin{array}{l}\text { Virgins: } 2.0 \pm 1.0(n=5) \\
\text { plugged, } 5.0 \pm 11.0(n=4) \\
U=0.5, p=0.04\end{array}$ & $\begin{array}{l}\text { Virgins, } 7.9 \pm 2.7(n=5) \\
\text { plugged, } 6.65 \pm 15.3(n=4) \\
U=7, p=0.99\end{array}$ \\
\hline Palpal displacement & $\begin{array}{l}\text { The female pushes the male's palp away } \\
\text { from her epigynum using her legs III }\end{array}$ & $\begin{array}{l}\text { Virgins, } 2.0 \pm 2.0(n=9) \\
\text { plugged, } 8.5 \pm 12.0 \quad(n=5) \\
U=0.5, p=0.01\end{array}$ & $\begin{array}{l}\text { Virgins, } 2.5 \pm 0.9(n=9) \text {; plugged, } \\
10.1 \pm 34.1(n=5) ; U=8.5, p=0.02\end{array}$ \\
\hline Hug the male & $\begin{array}{l}\text { The female embraces or hugs the male's body or } \\
\text { legs with her own legs, while chelicerae remain } \\
\text { locked and the male tries to escape. This behavior } \\
\text { often ends with the female wrapping the male body } \\
\text { with silk, similar to prey-wrapping behavior }\end{array}$ & Virgins, $n=10$; plugged, $n=5$ & - \\
\hline Palpal stuck & $\begin{array}{l}\text { The male's palp gets stuck to substances on female } \\
\text { genital plug and the male tries to withdraw it } \\
\text { using the other palp }\end{array}$ & Virgins, $n=7$; plugged, $n=3$ & - \\
\hline
\end{tabular}

We distinguish between trials with virgin and plugged females and show the results of the statistical comparisons between both groups (MannWhitney $U$ test). Sample sizes are shown in parentheses. The behaviors hug the male and palpal stuck occurred only once per copulation so we report only the number of copulations in which they occurred

both females and males. Frequency and duration of these behaviors are shown in Table 1. Male and female courtship occurred in all the trials, both with virgin $(n=32)$ and plugged females $(n=15)$. Courtship duration that ended with copulation did not differ significantly between virgins (median \pm quartile, $783.0 \pm 530.3 \mathrm{~s}$ ) and plugged females $\left(1,054.6 \pm 1,701.6 \mathrm{~s} ; \quad U=20, n_{1}=12, n_{2}=5, p=0.44\right)$. The courtship behaviors that occurred with highest frequency were bursts of male palpal rubbing, bursts of male twanging, and tapping the web by both females and males. These behaviors also had the longest durations, along with male tapping the female (Table 1). Both frequency and duration of courtship and copulation behaviors varied widely in virgin and plugged females. Male foreleg rubbing showed longer duration with plugged females compared to virgins (see Table 1), but other courtship behaviors did not differ between virgin and plugged females.

We did not find an effect of age of adult female on mating acceptance (age: median \pm quartile, $2.0 \pm 3.0$ days, range: $\left.1-5 ; U=8, n_{1}=12, n_{2}=2, p=0.65\right)$. Copulations occurred more frequently with virgins than with plugged females (Fisher's exact test: $p=0.03$ ). In 12 of 14 virgin females and in all plugged females $(n=12)$, both sexes locked their chelicerae together prior to copulation, as is typical for tetragnathids. The female closed her fangs on male's chelicerae, rather than the opposite. In all virgin females that locked their chelicerae, courtship ended with copulation. However, though all plugged females locked chelicerae and adopted the mating posture, and males always tried to insert their palps, only five of these females mated. Males mating with plugged females did not perform any behavior indicating plug extraction but they just punctured the genital plug with the embolus of the palp and made a slit to allow the insertion to occur. After puncturing, long insertions and hematodocha inflations occurred. Considering the total number of expositions with plugged females, puncturing the mating plug was more frequent when the plugged female was larger (median \pm quartile; female size when plug was formed, $2.2 \pm 0.7 \mathrm{~mm}$; female size when plug was not formed, $1.8 \pm 0.3 \mathrm{~mm} ; U=3$, $n_{1}=5, n_{2}=7, p=0.02$ ), but did not vary with male body size (median \pm quartile; male size when plug was formed, $1.6 \pm$ $0.3 \mathrm{~mm}$; male size when plug was not formed: $1.8 \pm$ $\left.0.2 \mathrm{~mm} ; U=19.5, n_{1}=5, n_{2}=7, p=0.95\right)$, or with sexual size dimorphism index (median \pm quartile; index when plug was formed: $0.8 \pm 0.1$; index when plug was not formed, $0.9 \pm$ $0.1 ; U=7, n_{1}=5, n_{2}=7, p=0.10$ ).

Copulation started when the male inserted the conductor of one of his palps onto one of the epigynum orifices, the hematodocha of the corresponding palp inflated and deflated with the cymbium hook positioned in the opposite epigynum aperture (see Fig. 1 for details on male genitalia). Copulation duration did not differ between virgin (median \pm quartile, $649 \pm 898 \mathrm{~s})$ and plugged females $(297 \pm 230 \mathrm{~s})$, possibly due to their high variances ( $U=20, n_{1}=12, n_{2}=5, p=$ 0.42). The copulation consisted on long insertions with 


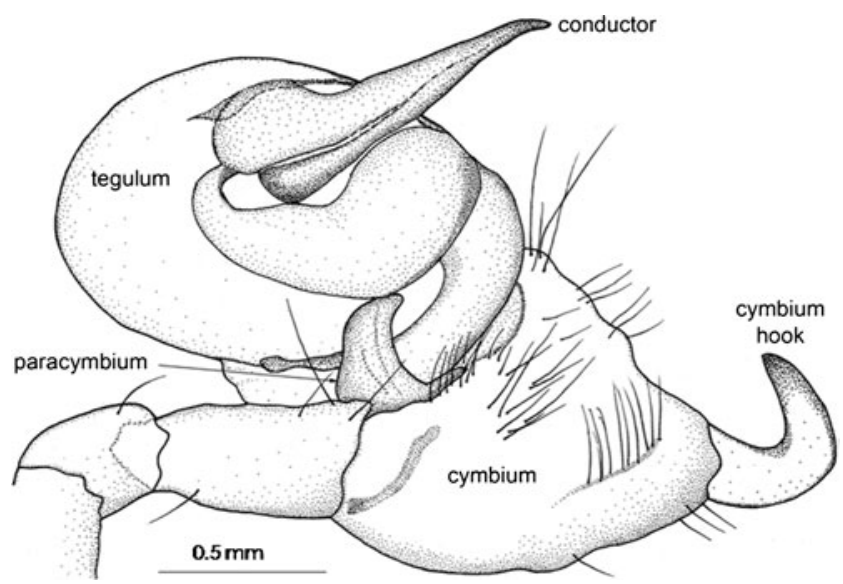

Fig. 1 Drawing of ventral view of left male palpal organ in L. argyra showing the conductor where the embolus projects during insemination and the cymbium hook that is placed simultaneously in the opposite aperture of the female epigynum

multiple hematodochal inflations (Table 2). Considering copulations with virgins and plugged females altogether, males performed an average of $1.5 \pm 0.7$ palpal insertions with the right palp and $1.3 \pm 0.5$ with the left palp. Only in two cases, the males performed a single palpal insertion. The frequency and duration of long insertions and hematodochal inflations did not differ between virgin and plugged females (Table 2). However, the number of flubs and the number and duration of palpal displacements were higher in plugged females.

In ten copulations with virgins and in all those of plugged females, copulation ended with the female embracing male legs and sometimes wrapping them with silk, with chelicerae still locked and with the male trying to escape (Table 2). Sexual cannibalism on males occurred in one case with a virgin and four cases with plugged females; cannibalism was more frequent with plugged females (Fisher's exact test, $p=0.04$ ). In all cases of cannibalism, both the female and the male had performed courtship and the female had locked the male's chelicerae. In the cases of cannibalism with plugged females, none of the males had punctured the mating plug before the attack. In one case with a virgin female, the fatal attack occurred post insertion, close to the end of copulation. Sexual size dimorphism index was not related to mating acceptance (virgins, $U=48, n_{1}=10, n_{2}=12, p=0.44$; previously plugged, $\left.U=16.5, n_{1}=7, n_{2}=5, p=0.93\right)$, or with the occurrence of cannibalism ( $\left.U=9, n_{1}=8, n_{2}=4, p=0.26\right)$.

Genital plug occurrence in relation with male performance

Of the 12 virgins that copulated, nine produced genital plugs (five were produced immediately after copulation, four were observed $24 \mathrm{~h}$ later). Of the plugged females that copulated, all of them produced an additional copulatory plug immediately after copulation. We did not observe the transfer of a whitish substance by males during copulation, as occurs in L. mariana (Eberhard and Huber 1998; Aisenberg and Eberhard 2009). However, we observed a whitish liquid emerging from the openings of the female genital ducts during copulation, during or after male insemination.

In seven trials with virgins and in three trials with plugged females, the male palp adhered to a whitish sticky substance that had extended on the female genital plate (Table 2) and the male had to struggle quite energetically to free his palp. In two cases, one with a virgin and one with a plugged female, the male's struggle to free his palp ended with the female cannibalizing him. Of the seven cases in which the male's palp adhered to the substance that emerged from the female genitalia during mating, in five occasions, the mating plug was formed immediately after copulation. However, in two cases, the substance had disappeared by the end of the copulation, but the plug was present $24 \mathrm{~h}$ later. Copulatory plugs appeared to solidify in a few seconds and covered totally or partially the female genital openings (Fig. 2). Virgin females produced four partial and five total plugs, but plugged females produced mating plugs that covered the entire epigynum in all cases. The two copulations with a single palpal insertion resulted in plug formation. Formation of total or partial plugs was not associated with the number of palpal insertions performed during copulation $\left(U=8, n_{1}=4\right.$, $n_{2}=5, p=0.99$ ).

We did not find a significant effect of most courtship and copulatory behaviors on mating plug formation (Table 3). The only exception was that plug formation occurred more frequently when males had a significantly higher number of bursts of twanging during courtship (Table 3). Copulation duration or female age had no effect on plug formation (copulation duration, $U=4, n_{1}=9 n_{2}=3, p=0.13$; female age, $\left.U=4.5, n_{1}=9 n_{2}=3, p=0.06\right)$.

\section{Discussion}

Sexual encounters involve substantial risks for L. argyra males. Cannibalism was more frequent when males were exposed to plugged females compared to virgins. In several trials (with both virgin and plugged females), the male's palp adhered to mating plug substances that emerged from the female's epigynum while the palp was still inserted. In two of these cases, the male was cannibalized by the female while he was trying to pull his palp free from the sticky substance. The substance that emerged from the female epigynum which later formed the copulatory plug could appear after few palpal insertions, after multiple insertions, immediately after 
Fig. 2 Epigynum of a female of L. argyra: a without copulatory plug (left), b with copulatory plug covering the two genital openings, one with a small and the other one with a large plug (right)
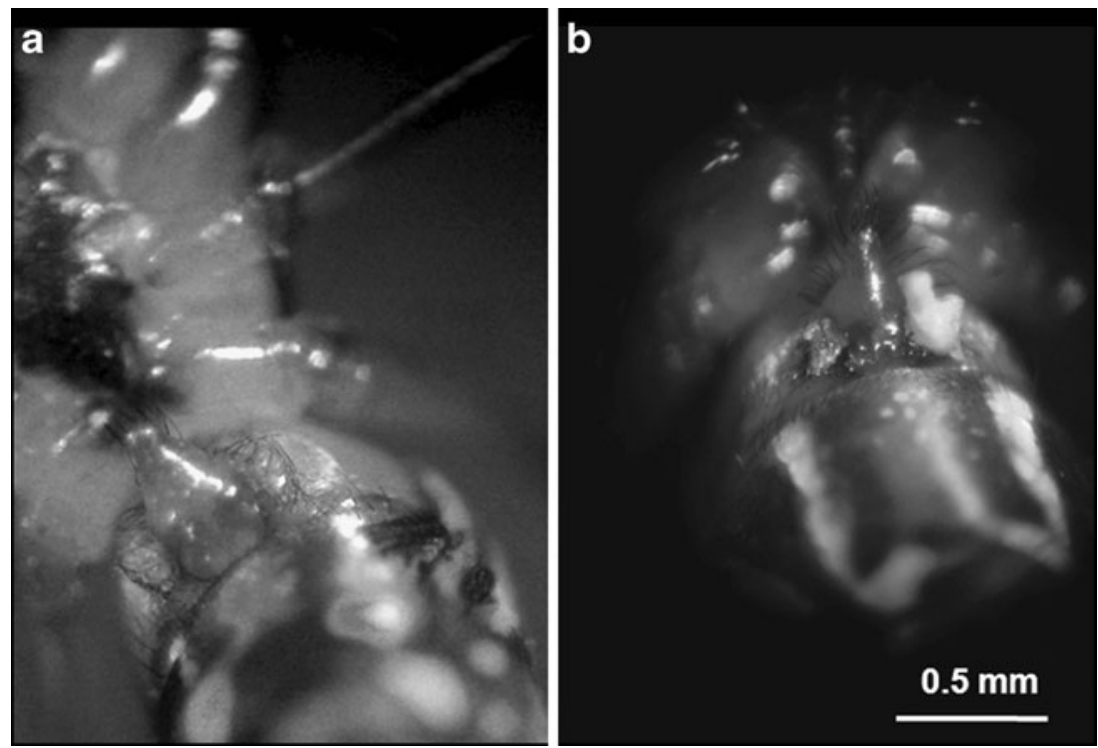

copulation, or during the next $24 \mathrm{~h}$. By initiating plug formation at different times during copulation, females might determine copulation duration and affect the possibilities of remating. Hence, this behavior of $L$. argyra resembles that of other species in which females attack or cannibalize males and thus define the duration of insemination and copulation (Elgar et al. 2000; Schneider and Elgar 2001; Fromhage et al. 2003). As

Table 3 Frequency and duration of courtship and copulatory behaviors in L. argyra (median \pm quartile) in virgins, distinguishing between trials in which plug formation occurred and did not occur

\begin{tabular}{|c|c|c|c|}
\hline Courtship behavior & Plug was formed & Plug was not formed & Statistics \\
\hline \multirow[t]{2}{*}{ Male jerk the web } & Occurrences, $3.5 \pm 6.0(n=6)$ & Frequency, $2.0(n=1)$ & Frequency $^{\mathrm{a}}$ \\
\hline & Duration, $13.3 \pm 18.8(n=6)$ & Duration, $33.8(n=1)$ & Duration $^{\mathrm{a}}$ \\
\hline \multirow[t]{2}{*}{ Bursts of palpal rubbing } & Occurrences, $32.0 \pm 43.4(n=9)$ & Occurrences, $17.0 \pm 3.2(n=9))$ & Frequency, $U=4.5, p=0.14$ \\
\hline & Duration, $200.4 \pm 71.7(n=3)$ & Duration, $133.9 \pm 115.6(n=3$ & Duration, $U=8, p=0.49$ \\
\hline \multirow[t]{2}{*}{ Female bursts of twanging } & Occurrences, $3.5 \pm 4.0 \quad(n=9)$ & Occurrences, $1.0 \pm 1.0(n=3)$ & Frequency, $U=4.5, p=0.17$ \\
\hline & Duration, $41.9 \pm 74.0(n=9)$ & Duration, $4.7 \pm 4.5(n=3)$ & Duration, $U=5, p=0.54$ \\
\hline \multirow[t]{2}{*}{ Male bursts of twanging } & Occurrences, $83.4 \pm 63.0(n=9)$ & Occurrences, $16.7 \pm 13.0(n=3)$ & Frequency, $U=1, p=0.03$ \\
\hline & Duration, $337.1 \pm 182.2(n=9)$ & Duration, $140.1 \pm 173.4(n=3)$ & Duration, $U=4, p=0.14$ \\
\hline \multirow[t]{2}{*}{ Female tap the web } & Occurrences, $9.5 \pm 3.0(n=6)$ & Occurrences, $3.0 \pm 1.0(n=3)$ & Frequency, $U=0, p=0.02$ \\
\hline & Duration, $65.4 \pm 81.6(n=6)$ & Duration, $11.7 \pm 13.6(n=3)$ & Duration, $U=2, p=0.09$ \\
\hline \multirow[t]{2}{*}{ Male tap the web } & Occurrences, $12.0 \pm 7.0(n=9)$ & Occurrences, $8.0 \pm 4.0 \quad(n=3)$ & Frequency, $U=4.5, p=0.14$ \\
\hline & Duration, $80.1 \pm 121.1(n=9)$ & Duration, $22.5 \pm 74.2(n=3)$ & Duration, $U=5, p=0.19$ \\
\hline \multicolumn{4}{|l|}{ Copulatory behavior } \\
\hline \multirow[t]{2}{*}{ Long insertions } & Occurrences, $2.5 \pm 1.5(n=9)$ & Occurrences, $3 \pm 3(n=3)$ & Frequency, $U=7, p=0.31$ \\
\hline & Duration, $313.0 \pm 246.5(n=9)$ & Duration, $393.0 \pm 100.0(n=3)$ & Duration, $U=10, p=0.77$ \\
\hline \multirow[t]{2}{*}{ Inflations } & Occurrences, $203.5 \pm 129.5(n=9)$ & Occurrences, $230.0 \pm 72.0(n=3)$ & Frequency, $U=7, p=0.38$ \\
\hline & $\begin{array}{l}\text { Duration, coincides with long } \\
\text { insertions duration }\end{array}$ & $\begin{array}{l}\text { Duration, coincides with long } \\
\text { insertions duration }\end{array}$ & Duration, - \\
\hline \multirow[t]{2}{*}{ Flubs } & Occurrences, $2.0 \pm 1.0(n=4)$ & Occurrences, $2(n=1)$ & Frequency $^{\mathrm{a}}$ \\
\hline & Duration, $7.4 \pm 9.1(n=4)$ & Duration, $7.94(n=1)$ & Duration $^{\mathrm{a}}$ \\
\hline \multirow[t]{2}{*}{ Palpal displacements } & Occurrences, $2.0 \pm 2.0 \quad(n=9)$ & Occurrences, - & Frequency $^{\mathrm{a}}$ \\
\hline & Duration, $2.5 \pm 0.9(n=9)$ & Duration, - & Duration $^{\mathrm{a}}$ \\
\hline
\end{tabular}

We provide sample sizes in parentheses and the results of the statistical comparisons between both groups (Mann-Whitney $U$ test)

${ }^{\text {a }}$ Insufficient sample size to perform statistical comparisons 
far as we know, this is the first observation of a mating plug that functions as a sticky mortal trap for males. In addition, most copulations ended with females trying to seize or wrap the males as preys while they were trying to escape. This female aggression is apparently not an artifact of captivity, as two courtships and copulations in the field also involved apparently highly aggressive behavior by the female (WG Eberhard, unpublished data), and three additional adult females were observed feeding on adult males at the wild ( $G$ Barrantes, unpublished data).

The association between male twanging during courtship and plug formation, the high levels of sexual cannibalism, and the initiation of plug formation at different stages during mating (with the consequent risks for males of getting trapped), suggest that male sexual behavior could be under selection through cryptic female choice (Eberhard 1991, 1996). Females could exert extreme mate choice (Elgar and Nash 1988; Schneider and Elgar 2005) and decide to cannibalize or mate based on male twanging and/ or plug-puncturing performance. On the other hand, as a consequence of the high mating risks, males could also be selective when making mating decisions, as has been reported for other spider species (Herberstein et al. 2002; Rypstra et al. 2003; Gaskett et al. 2004; Andrade and Kasumovic 2005; Stoltz et al. 2007; Baruffaldi and Costa 2009; Pruitt and Riechert 2009; Schulte et al. 2010). Males mated more frequently with virgin females and they were more successful in perforating plugs of larger females. This could be a result of higher mating effort towards females with characteristics that in spiders are associated with higher fecundity expectations (Uhl et al. 2005). However, it is difficult to determine if mating behavior in L. argyra is under female or male control, or if both play a role in this context.

We did not find evidence of male transfer of components of the mating plug as occurs in L. mariana (Eberhard and Huber 1998; Méndez 2004; Aisenberg and Eberhard 2009). In addition, copulation in $L$. argyra did not include short palpal insertions, and these insertions in L. mariana are associated with male transfer of plug substances (Eberhard and Huber 1998; Méndez 2004). Preliminary observations indicate that the mating plugs in L. argyra do not include encapsulated or decapsulated sperm and appear to be composed exclusively of female substances (A. Aisenberg, G. Barrantes, W.G. Eberhard, unpublished data). However, male transference of sperm associated compounds needed for mating plug formation could have been undetected by our observations, so new studies are needed to address these topics.

In general, courtship behavior did not differ between virgin and plugged females with the exceptions of a higher frequency of foreleg rubbing, and a higher frequency and duration of palpal displacements in plugged females. Palpal displacements are female movements performed with legs III intended to remove male palps away from the epigynum. So, the higher frequencies and duration of palpal displacements in plugged females agree with a reduction in sexual receptivity in these females. A reduction in sexual receptivity in mated females has been described for other spider species (Helsdingen 1965; Jackson 1980; Elgar and Bathgate 1996; Andrade and Banta 2002; Schäfer and Uhl 2005; Aisenberg and Costa 2005). However, as occurs in the tetragnathid Glenognatha emertoni (Danielson-François 2006), in L. argyra copulations of virgin and plugged females did not differ in mating occurrences, total number of palpal insertions, or copulation duration. The higher number of flubs during copulations of plugged females could be the result of males trying to remove the female's mating plug, hypothesis that requires further observations.

Plugged females performed courtship behaviors, adopted mating posture, and locked chelicerae in all the cases, but only in $41.6 \%$ of these cases mating occurred. The reduced frequency of successful copulations in plugged females indicates that mating plugs in $L$. argyra probably function as barriers that reduce, at least during a certain period, other males' mating access. Males did not remove copulatory plugs as has been described for other spiders, in which males spend long periods of time extracting the genital plug (Jackson 1980; Masumoto 1993; Uhl et al. 2010). Copulation occurred with plugged females when males succeeded in making a slit through the mating plug (apparently with the conductor), while holding firmly to the female chelicerae. The fact that males were more efficient in puncturing the copulatory plugs of larger females could imply that larger females are preferred by males, that larger females have more fragile plugs, or that these females are more willing to accept rematings. This last possibility has been reported for several taxa (Masumoto 1993; Gage 1998; Bergström et al. 2002; Schäfer and Uhl 2005; Aisenberg et al. 2009; Aisenberg 2009). We did not document, however, whether sperm transfer really occurred in the copulations we observed though they showed similar behavioral patterns to those of virgin females. Sperm counts will help answer these questions.

Finally, Leucauge is a very promising genus for studies on sperm competition, female choice, and the evolution of sexual strategies. Detailed studies on the behavior looking for similarities and differences in sexual strategies, genital morphology and ecology between the species, and considering variables such as male and female age and reproductive history, will help disentangle the pressures driving female participation in mating plug formation and male adaptations to overcome sperm competition in this spider genus. 
Acknowledgments We are deeply grateful to WG Eberhard for encouraging us to carry out the present study, for enthusiastic discussions, and for critically reading the manuscript and improving the English. We thank Pedro Gaspar for permitting us to work in his oil palm plantation. We also acknowledge three referees and the Editor Sven Thatje that with their suggestions improved the final version of the manuscript. Jairo Moya-Ramírez, Andrés Rojas, Marianela Solís Del Valle, and Ju Lin Weng for their help during field work. The Smithsonian Tropical Research Institute supported AA with a Stanley Rand Fellowship.

\section{References}

Abramson JH (2004) WINPEPI (PEPI-for-Windows): computer program for epidemiologists, version 6.8 [cited October 2010]. Available from: http://www.brixtonhealth.com/pepi4windows.html

Aisenberg A (2009) Male performance and body size affect female re-mating occurrence in the orb web spider Leucauge mariana (Araneae, Tetragnathidae). Ethology 115:1127-1136

Aisenberg A, Costa FG (2005) Females mated without sperm transfer maintain high sexual receptivity in the wolf spider Schizocosa malitiosa. Ethology 111:545-558

Aisenberg A, Eberhard WG (2009) Possible cryptic female choice in a spider: female cooperation in making a copulatory plug depends on male copulatory courtship. Behav Ecol 20:1236-1241

Aisenberg A, Estramil N, Toscano-Gadea C, González M (2009) Timing of induced female reluctance and male adjustment of copulatory behaviour under sperm competition risk in the wolf spider Schizocosa malitiosa. J Ethol 27:43-50

Andrade MCB (1996) Sexual selection for male sacrifice in the Australian redback spider. Science 240:70-72

Andrade MCB, Banta EM (2002) Value of male remating and functional sterility in redback spiders. Anim Behav 63:857-870

Andrade MCB, Kasumovic MM (2005) Terminal investment strategies and male mate choice: extreme tests of Bateman. Int Comp Biol 45:838-847

Baruffaldi L, Costa FG (2009) Changes in male sexual responses from silk cues of females at different reproductive states in the wolf spider Schizocosa malitiosa. J Ethol 28:75-85

Bergström J, Wiklund C, Kaitala A (2002) Natural variation in female mating frequency in a polyandrous butterfly: effects of size and age. Anim Behav 64:49-54

Blumstein DT, Evans CS, Daniel JC (2000) JWatcher 0.9. An introductory user's guide. Available from: http://galliform.psy. mq.edu.au/jwatcher/

Boorman E, Parker GA (1976) Sperm (ejaculate) competition in Drosophila melanogaster, and the reproductive value of female of remating to male in relation to female age and mating status. Ecol Entomol 1:145-155

Castro TJ (1995) Estudio comparativo del comportamiento reproductor, en las arañas del género Leucauge (Araneae: Tetragnathidae), del Soconusco, Chiapas. Graduate Thesis, Universidad de Ciencias y Artes del Estado de Chiapas, México

Danielson-François AM (2006) Natural history of Glenognatha emertoni (Araneae, Tetragnathidae): mating behavior and sperm release in a haplogyne. J Arachnol 34:387-398

Drummond BA (1984) Multiple mating and sperm competition in the Lepidoptera. In: Smith RA (ed) Sperm competition and the evolution of animal mating systems. Academic Press, New York, pp 291-371

Eberhard WG (1991) Copulatory courtship and cryptic female choice in insects. Biol Rev 66:1-31
Eberhard WG (1994) Evidence for widespread courtship during copulation in 131 species of insects and spiders, and implications for cryptic female choice. Evolution 48:711-733

Eberhard WG (1996) Female control: sexual selection by cryptic female choice. Princeton University, Princeton, New Jersey

Eberhard WG (2001) Under the influence: webs and building behavior of Plesiometa argyra (Araneae, Tetragnathidae) when parasitized by Hymenoepimecis argyraphaga (Hymenoptera, Ichneumonidae). J Arachnol 29:354-366

Eberhard WG, Huber BA (1998) Courtship, copulation and sperm transfer in Leucauge mariana (Araneae, Tetragnathidae) with implications for higher classification. J Arachnol 26:342-368

Eberhard WG, Guzmán-Gómez S, Katley K (1993) Correlation between genitalic morphology and mating systems in spiders. Biol J Linn Soc 50:197-209

Eberhard WG, Huber BA, Rodríguez SRL, Briceño RD, Salas I, Rodríguez V (1998) One size fits all? Relationships between the size and degree of variation in genitalia and other body parts in twenty species of insects and spiders. Evolution 52:415-431

Elgar MA, Bathgate R (1996) Female receptivity and male mateguarding in the jewel spider Gasteracantha minax Thorell (Araneidae). J Insect Behav 9:729-738

Elgar MA, Nash DR (1988) Sexual cannibalism in the garden spider Araneus diadematus. Anim Behav 36:1511-1517

Elgar MA, Schneider JM, Herberstein ME (2000) Female control of paternity in the sexually cannibalistic spider Argiope keyserlingi. Proc R Soc Lond B 267:2439-2443

Foelix RF (1996) Biology of spiders. Oxford University Press, New York

Foellmer MW, Fairbairn DJ (2004) Males under attack: sexual cannibalism and its consequences for male morphology and behaviour in an orb-weaving spider. Evol Ecol Res 6:163-181

Fromhage L, Uhl G, Schneider JM (2003) Fitness consequences of sexual cannibalism in female Argiope bruennichi. Behav Ecol Sociobiol 55:60-64

Gage MJG (1998) Influences of sex, size, and symmetry on ejaculate expenditure in a moth. Behav Ecol 9:592-597

Gaskett AC, Herberstein ME, Downes BJ, Elgar MA (2004) Changes in male mate choice in a sexually cannibalistic orb-web spider (Araneae: Araneidae). Anim Behav 141:1197-1210

Gomiendo M, Harcourt AH, Roldán ERS (1998) Sperm competition in mammals. In: Møller AP, Birkhead TR (eds) Sperm competition and sexual selection. Academic Press, London, pp 667-756

Hammer O, Harper DAT, Ryan PD (2003) Past Palaeontological, version 1.18. Available from: http://folk.uio.no/ohammer/past

Helsdingen PJ (1965) Sexual behaviour of Lethyphantes leprosus (Ohlert) (Araneida, Linyphiidae), with notes on the function of the genital organs. Zool Meded 41:15-42

Herberstein ME, Schneider JM, Elgar MA (2002) Costs of courtship and mating in a sexually cannibalistic orb-web spider: female mating strategies and their consequences for males. Behav Ecol Sociobiol 51:440-446

Huber BA (1995) The retrolateral tibial apophysis in spiders-shaped by sexual selection? Zool J Linn Soc 113:151-163

Huber BA (2005) Sexual selection research on spiders: progress and biases. Biol Rev 80:363-385

Jackson RR (1980) The mating strategy of Phidippus johnsoni (Araneae, Salticidae): II. sperm competition and the function of copulation. J Arachnol 8:217-240

Knoflach B (1998) Mating in Theridion varians Hahn and related species (Araneae: Theridiidae). J Nat Hist 32:545-604

Leonard JL, Córdoba-Aguilar A (2010) The evolution of primary sexual characters in animals. Oxford University Press, USA

Masumoto T (1993) The effect of the copulatory plug in the funnelweb spider, Agelena limbata (Araneae: Agelenidae). J Arachnol 21:55-59 
Mattoni CI, Peretti AV (2004) The giant and complex genital plug of the asper group of Bothriurus (Scorpiones, Bothriuridae): morphology and comparison with other scorpion genital plugs. Zool Anz 243:75-84

Méndez V (2004) Comportamiento sexual y dinámica de población de Leucauge mariana (Araneae: Tetragnathidae). MSc Thesis, Universidad de Costa Rica, Costa Rica

Moya-Laraño J, Cabeza M (2003) Bimodality in the body size distribution of Mediterranean tarantula juveniles: Humphreys' Russian roulette revisited. Rev Ibér Aracnol 7:211-219

Pruitt JN, Riechert SE (2009) Male mating preference is associated with risk of pre-copulatory cannibalism in a socially polymorphic spider. Behav Ecol Sociobiol 63:1573-1580

Robinson MH, Robinson B (1980) Comparative studies of the courtship and mating behavior of tropical araneid spiders. Pac Insects Monogr 36:1-218

Rypstra AL, Wieg C, Walker SE, Persons MH (2003) Mutual mate assessment in wolf spiders: differences in the cues used by males and females. Ethology 109:315-325

Schäfer MA, Uhl G (2005) Sequential mate encounters: female but not male body size influences female remating behavior. Behav Ecol $16: 461-466$
Schneider JM, Elgar MA (2001) Sexual cannibalism and sperm competition in the golden orb-web spider Nephila plumipes (Araneoidea): female and male perspectives. Behav Ecol 12:552-574

Schneider JM, Elgar MA (2005) The combined effects of pre- and post-insemination sexual selection on extreme male body size variation. Evol Ecol 19:419-433

Schulte KF, Uhl G, Schneider JM (2010) Mate choice in males with one-shot genitalia: limited importance of female fecundity. Anim Behav 80:699-706

Simmons LW (2001) Sperm competition and its evolutionary consequences in the insects. Princeton University Press, Princeton, New Jersey

Stoltz JA, McNeil JN, Andrade MCB (2007) Males assess chemical signals to discriminate just-mated females from virgins in redback spiders. Anim Behav 74:1669-1674

Uhl G, Schmitt S, Shäfer M (2005) Fitness benefits of multiple mating versus female mate choice in the cellar spider (Pholcus phalangioides). Behav Ecol Sociobiol 59:69-76

Uhl G, Nessler SH, Schneider JM (2010) Securing paternity in spiders? A review on occurrence and effects of mating plugs and male genital mutilation. Genetica 138:75-104

Wigby S, Chapman T (2004) Sperm competition. Curr Biol 14:100-103 